\title{
Socio-psychological problems of society and education in a transitive-turbulent society
}

\author{
Tatyana Skripkina ${ }^{1, *}$ \\ ${ }^{1}$ Russian State University of Humanities, Miusskaya square, 6, Moscow, 125993, Russia
}

\begin{abstract}
This article is devoted to the analysis of socio-psychological problems of modern society. Modern society in this article is interpreted as transitive-turbulent, which is associated with the transition stage in the era of postmodernism. The work is aimed at finding methodological foundations for analyzing the features of modern society, as well as analyzing the problems associated with the new cultural ethics of a modern dehumanized society. The new realities associated with instability, multivariability and uncertainty of the future have given rise to many personal and sociopsychological problems. In new realities, people are looking for ways to cope with them. The article shows that the biggest troubles in these conditions are faced by teenagers and young people, for whom the most important age task is the formation of personal identity in conditions of multifactorial and uncertain future and blurring moral norms. In connection with these circumstances, education has an extremely difficult task associated with human formation in new socio-cultural conditions. The main purpose of this article is to reveal, identify and analyze the psychological problems associated with changing the social behavior of both individuals and various groups in a transitive-turbulent society.
\end{abstract}

\section{Introduction}

Over the past 15-20 years, the diverse and unpredictable world in which we live has changed unusually. It was filled with new meanings and new cultural ethic. The trend of ordinary consciousness was concepts that used to be found in scientific works only, such as xenophobia, intolerance, cruelty, aggression, vandalism, rationalism, pragmatism. Therefore, actual social order was formed to study these phenomena. The sociocultural situation has changed and the laws by which society lives are rapidly changing. There are hundreds of examples where the cruelty of people's ordinary behavior strikes the imagination. Many humanistic values that used to seem natural and immaculate and that were studied by many scientists, such as altruism, empathy, justice, friendship, pity, honesty, cooperation, solidarity, began to seem outdated, archaic and poorly working in society. Whatever is happening to culture and why has cultural ethics changed so rapidly?

The changes in Russian society are probably due to the fact that Russia currently occupies an intermediate position, it is in the process of moving from an industrial society to a postindustrial one. And this transition turned out to be very painful, in the words of the Polish

\footnotetext{
*Corresponding author: skripkinaurao@mail.ru
} 
anthropologist and culturologist P. Shtomka "culturally traumatic" [1]. But it is hoped that the trauma will eventually heal and our society will enter a post-industrial world that recognizes humanistic values as the leaders, otherwise we simply will not survive.

\section{Materials and methods}

The modern post-industrial stage of the development of civilization is accompanied by the formation of a new cultural situation, called postmodernism, which is rapidly manifested in all spheres of culture and science. Its fundamental idea is an orientation towards humanistic principles related to the recognition of cultural diversity, pluralism of opinions, planetary thinking, and environmental protection.

As a result, in the modern world there was a radical reevaluation of many norms and stereotypes related to the ethics of the meaning of life that seemed to have been established for years, relationship between sexes, understanding of freedom of expression, traditions of rationality. These changes have occurred with the direct influence of the new culture, the culture of postmodernism.

The peculiarities of the culture of post-industrial society, its methodological, theoretical and applied aspects have been analyzed many times by representatives of social sciences, both foreign and domestic. Among foreign researchers, the most famous were the works of W. Beck [2], T. Parsons [3], S. Eisenstadtf [4], A. Gershenkron [5], B. Moore [6], P. Stompka [1] and many others. In social sciences, the most recognized among Russian authors are the works of A.S. Akhiezer [7], N.V. Zubarevich [8], E.A. Orlova [9] and others.

In numerous attempts to understand this problem, huge theoretical experience has been accumulated in analyzing the processes of transition from a traditional to an industrial society, various scenarios arising on the way have been analyzed, general patterns and features related to the specifics of society and the country entering post-modern are revealed.

The new cultural situation could not but affect science, in the form of a global restructuring of the hierarchy of scientific knowledge methods, the recognition of their fundamental pluralism, and the formation of an attitude to the complementarity of fundamental, applied, rational-secular and religious-mythological knowledge.

Education, as a huge part of culture related to the development of the country's main strategic potential, cannot be left out. Youth is not an untimely entity, its formation, its human formation occurs in certain socio-cultural conditions set by the framework of the culture within which it develops. Education in the broadest sense plays the role of a moderator in creating a picture of the world of the younger generation.

It should be very difficult for the younger generation to "become" to self-develop at the turning point of familiar cultural traditions. And the more important is the role of education and educational institutions, which themselves are in the state of constant reform.

The cultural turn that took place is like a tectonic shift, it has changed the concept of rationality, objectivity, the idea of the ratio of objective and subjective, the idea of the scientific picture of the world, as well as the patterns of the formation of an individual picture of the world of each particular person.

The cultural turn, first of all, is associated with epistemological shifts that have occurred in the social sciences. Changes in the understanding of the very nature of scientific objectivity, the development of post-classical knowledge, constructionism, postmodernism and post-structuralism are called cultural turn.

The attitude towards scientific knowledge has also changed in connection with the adoption of the idea of instability, as well as the recognition of the temporality and multiplicity of knowledge excluding determinism. When building knowledge, the social subject is given priority as a source of transformation. 
In the system of social knowledge special role is given to psychological knowledge associated with the post-classical period of its development. The understanding of the essence of man has changed dramatically, which is interpreted as a self-developing, open, selforganizing system, which inevitably involves into psychological research the study of a number of problems, the solution of which cannot be worked out outside the anthropological understanding of the essence of man. When constructing knowledge, the social subject is considered as a source of basic transformations. The understanding of cultural norms as a basis for mutual understanding based on ideas of cultural diversity is being rethought. New models of interpretation are being constructed, based on a growing variety of views on the world, and knowledge is understood as interpretation.

The society of transition has long been characterized in science as a society of transitivity. The discourse of transitivity has long entered the sphere of interests of many humanities. When they talk about a transitive society, they mean the transitional state of society together with the social transformations taking place in it. At present, a sufficient number of studies on this issue have already accumulated in the humanities [see, for example, 10, 11,12]. Transitive philosophy, economics, sociology appeared. However, in our opinion, at present there is absolutely insufficient socio-psychological research devoted to the study of the peculiarities of the person, of his/her behavior, transformations of his/her inner world, his/her social interactions in the transition period [13]. We must not forget that the human world is a symbolic reflection of social reality, so it is always associated with social changes that do not change the picture of reality.

The main purpose of this work is to reveal and indicate psychological problems associated with the behavior of both individuals and various groups in a transitive society.

\section{Results}

When they talk about the transitivity of Russian society, they mean the transition from an industrial society to a post-industrial one, in the social aspect, from an authoritarian society to a democratic one. If this project is meant, then the question of the kind of democracy arises, since in the humanities there are a rather large number of concepts and ideas about democracy, because democracy and permissiveness are not the same, however, there are very delicate differences between them.

From a methodological point of view, for psychological science, the methodological basis for understanding transitive society is the concept of social constructivism. Social constructivism becomes an explanatory mechanism for introducing social innovation, risk management, relativism of values and, ultimately, the design of a "decent future" that involves reaching the desired paths of development.

Let us briefly dwell on some significant characteristics of the transition period, which are associated with new challenges that give rise to huge psychological and personal problems in society.

One of the main characteristics of transition periods is that these periods are always accompanied by acute uncertainty about the future, which is difficult to predict, both at the level of society and at the level of an individual, since a person falls into a state of multiplicity of worlds, most of which are probabilistic [14].

In this regard, a transitive society is characterized by the difficulties of adapting and readapting to the constantly changing rules of the game. Obviously, uncertainty in predicting the future is associated with certain psychological changes in the personality and is associated with personal and emotional instability. However, a person is forced to somehow cope with this. In this regard, in recent years, the concept of pre-adaptation has come into scientific use. Thanks to the theory of open non-equilibrium systems, it has become possible to understand the phenomenology of non-adaptive manifestations not only in biology, but also in such 
humanities as sociology and psychology [15]. Thus, the authors of this article argue that "preadaptation to uncertainty is a key tool for generating redundancy of cognitive biological, cognitive, social and psychological diversity" [ibid., p. 3], and in general, pre-adaptation is the main mechanism ensuring readiness for change. Thus, the ability to adapt to the uncertainty of the future arises.

To this we can add that transit is always associated with the generation of a huge number of contradictions in social space related to social instability due to the repeated restructuring of a seemingly established social system, which forces a person to look for life meanings again and again, structure social reality and form new identities. As a result of all the indicated characteristics of a transitive society, it becomes unstable and acquires the features of turbulence. In philosophy, they even began to talk about the new type of personality "Homozwischens" (from the German "between" Yu.A. Harin). The so-called "zwischens" are people forced to make risky decisions in a situation of uncertainty [16]. A lot is changing in the social environment: the system of relations, leading values, patterns of behavior, features of communication, assessment of actions, etc. However, all this needs to be consolidated into a kind of holistic picture of the world. According to some authors, "the human world and ways of communication become the basis of a value-normative consensus as a prerequisite for a new society with a relatively stable structure" [17].Characterizing the features of transitive society, it is impossible not to dwell on the concept of risk, which has been widely known in foreign social science in recent decades, the founders of which are $\mathrm{N}$. Luman [18], E. Guiddens [19], W. Beck [2] and M. Douglas [20].

According to W. Beck, who is considered a leader in the study of society as a society of risks, modern risks are universal and fatal [2].

Based on this concept, the basic motivation of a person becomes the ideal of security, in exchange for the ideal of equality, since all kinds of risks are produced along with the benefits, which, like society, are globalized. All this changes the logic of thinking, and social relations alongside. In social relations, there are fundamental shifts related to the value of individualization, belief in one's own success at all costs. All this greatly increases competition and competition in society, which creates constant conflicts, increases tension, as well as aggression, cruelty and intolerance. All this, in turn, creates risks associated with global changes in the value system, especially in the moral sphere.

One of the ideologists of the concept of society at risk M.Douglas [20] shows in his work that the main shifts in the behavior and culture of society are that the dominant behavioral patterns are survival strategies and resistance to change, which is connected with the complete absence of civic initiatives. People individualize, the so-called atomic society arises.

Global risks are also characteristic of modern Russian society (E.M.Babosov [21], N.L.Smakotina [22], K.A. Feofanov [23], O.N. Yanitsky [24], etc.). These authors characterize Russian society as a society of social mistrust, in which the cocoon of "fundamental trust" is destroyed, only vertical connections operate in the social structure to the detriment of horizontal ones, which creates a decrease in the sense of responsibility and deprives society of the ability to organize itself.

This includes an increase in xenophobia, ethnophobia, migrantfobia and other social risks that further increase the potential for hostility in the social structure of society. All this leads to the erasure of the boundaries allowed in social behavior, a decrease in general culture, the denial of morality and the "erosion" of moral norms.

At the same time, many researchers note that the specificity of Russia is a strong internal heterogeneity, both socio-economic and sociocultural and related unevenness of regional development [9] (N.V. Zubarevich). At the same time, Rossi does not have a single cultural code of the country, since it is not only multi-ethnic, but also multi-religious, which significantly complicates the consolidation processes. 


\section{Discussion}

Thus, the human world created as a result of human activity is characterized by contradictions, tension, and constantly emerging centers of violence, aggression, xenophobia. The Russian Federation is not an exception.

The relatively new socio-psychological problems caused by this year's pandemic can be added to these problems. From our point of view, they can include a new perspective of the problem of risk propensity. It is known from social psychology that group behavior increases risk propensity. The universal risk showed that everything is not so clear. As it turned out, the universality of risk does not unite people, but, on the contrary, to a certain extent, separates them, both at the level of large groups and even states, and at the level of small groups. Individualism wins when it comes to universal risk. Thus, the peculiarities of people's behavior in a situation of universal risk becomes a new completely unexplored problem in social psychology.

It is precisely because of all the indicated characteristics that modern society becomes not only transitive, but also transitive-turbulent, in which a huge mass of people becomes socially traumatized, which explains the manifold increased demand for counselling and psychotherapeutic services.

The outlined characteristics of modern Russian society cannot bypass the main institutions of the state. This applies primarily to the institute of education. It is known that educational practices in any state fulfill the global task of forming a scientific and ordinary picture of the world in the younger generation. It is education that plays the role of a moderator in the process of human formation and the formation of a picture of the world of the younger generation. Defining the role of education in turbulent society, Chernykh S.I., Borisenko I.G. write: "... most often social turbulence is experienced by those social institutions that are "tied" to the direct reproduction of human capital. The main ones are education and learning as its most important element. "[25, c.97]

Socialization of each generation occurs from certain socio-cultural conditions set by the framework of culture. It should be very difficult for the younger generation to "become," self-develop at a cultural fracture. And the more important is the role of educational institutions, which themselves are in a state of constant reform, and therefore, like all other social institutions, is prone to turbulence, as evidenced by the continuous reform of educational institutions at all levels. Here it is appropriate to refer to a report published by UNESCO back in 1996, entitled "Education: a hidden treasure,"[26] which states in particular that "a large number of successive reforms actually kill reform, as they do not allow all actors involved in reform, to become participants in reforms, educational actors are disoriented and not disposed to the adoption and implementation of reforms "(ibid. Page 3).

The life of each educational institution is a micro-model of society, a micro-model of its culture.

Due to the circumstances outlined in the modern school, there are many negative problems associated with the atmosphere of intransigence of cruelty, bullying, the inability to effectively resolve conflicts, the failure of children to accept each other on the basis of ethnicity and confession, and even with increased attempts at suicide.

In this regard, the problem arises of designing such social reality in the educational environment that would act as a resource for ensuring safety and psychological comfort for each child.

Especially large difficulties arise with groups of older adolescents, for whom, as we know, the formation of personal identity becomes the most important psychological neoplasm.

It is at this age stage that the teenager chooses what to be. The answer to the question is very complex: how to be a teenager in a situation of multifactorial and uncertainty of 
formation [27]. Many of them have already developed attitudes related to the rightness of the "position of power," intolerance and categorical judgment. The worst thing is the emergence of hatred among some adolescents for certain social groups, with all the ensuing circumstances associated with extreme forms of reprisal against the hateful. Teenagers are already beginning to see a "discrepancy" between what is happening in their lives and what they are being taught.

To confirm the last thesis, we will briefly focus on the results of the research we conducted in 2019 on the values of older adolescents from families with different property positions. When ranking terminal values, almost all adolescents put the family in the first place, and material well-being in second. But at the same time, the values of career, interesting work and profession remained far behind. Thus, the conclusion suggests itself: a huge part of adolescents are not inclined to associate material well-being with labor and profession. At the same time, we note one important feature in our opinion. In this study, adolescents from different regions took part: Moscow, Rostov-on-Don and Ulan-Ude. The study showed that the richer the region, the stronger the mentioned discrepancy is. As the study showed, the smallest discrepancy between material well-being and the value of work and career was noted in adolescents living in a relatively poor region - Ulan-Ude.

And as a relatively new thing in the value sphere of adolescents, one can distinguish the fact that the vast majority of adolescents put the family in the first place. We tend to interpret this indicator as follows: adolescents feel instability, the turbulence of society and try to unconsciously rely on life, on something more stable and understandable.

\section{Conclusions}

So, the analysis showed that modern society, which is in the process of transitivity, is characterized by extreme instability, turbulence, which gives rise not only to a mass of sociopsychological problems, but also to a global change in the usual lifestyle, social behavior and, in general, world view of many people.

\section{References}

1. P. Stompka, SocIs 1, 6-16 (2001)

2. W. Beck, Risk Society: On the way to a different Art Nouveau (Progress-Tradition, Moscow, 2000)

3. T. Parsons, Social System (Academic Project, Moscow, 2018)

4. S. Eisenstadtf, Emergency reserve 6(74), 1-19 (2010)

5. A. Gershenkron, Economic backwardness in the historical perspective (Scientific Delo RANEPA, Moscow, 2015)

6. B. Moore, The social origins of dictatorship and democracy. The role of the landowner and peasant in the creation of the modern world (Higher School of Economics, Moscow, 2016)

7. V.S. Achiezer, Questions of philosophy 9, 29-45 https://elibrary.ru/item.asp?id=23025183

8. N.V. Zubarevich, Regions of Russia: inequality, crisis, modernization (Independent Institute of Social Policy, Moscow, 2010)

9. E.A. Orlova, Sociocultural prerequisites for modernization in Russia: Library in an era of change: Inform. booklet. (Digest) 2(10), 7 (2001) 
10. S.I. Chernykh, I.G. Borisenko, Higher education in the modern world: history and prospects: International interdisciplinary collective monograph (EncyclopedistMaximum, Moscow, 2020)

11. E.A. Nazarova, Bulletin of RUDN. Series: Sociology 18(2), 361-367 (2018)

12. E.V. Shchekotin, Society and power 1(57), 87 https://cyberleninka.ru/article/n/sotsialnoe-upravlenie-v-turbulentnom-obschestvevoprosy-bezopasnosti-i-riska

13. T.D. Martsinkovskaya, Psychol. Research 8(42), 1 http://psystudy.ru/index.php/num/2015v8n42/1168-martsinkovskaya42.html

14. A.G. Asmolov, Psychol. Research 8(40), 1 (2015) http://psystudy.ru

15. A.G. Asmolov, E.D. Shekhter, A.M. Chernorizov, Psychology issues 4, 3-26 (2017)

16. Yu.A. Kharin, Modern Zwischenism: the realities and prospects of man as a socioanthropic reality. Subjective claims and objective logic in the development of society of a transitional type (Grodno State University named after Yanka Kupala, Grodno, 1998)

17. M.G. Fedotova, Vyatka State University Bulletin Social philosophy 1(4), 28-31 (2010) https://cyberleninka.ru/article/n/k-soderzhaniyu-ponyatiya-tranzitivnoe-obschestvo

18. N. Luhmann, THESIS 5 (1994)

19. E. Giddens, Consequences of modernity. New post-industrial wave in the West: Anthology (Academia, Moscow, 1999)

20. M. Douglas, THESIS 5, 250 (1994)

21. E.M. Babosov, Fundamentals of the ideology of the modern state (Amalfeya, Minsk, 2003)

22. N.L. Smakotina, Fundamentals of sociology of instability and risk. Philosophical, sociological and socio-psychological aspects (MIEM, Moscow, 2009) https://cyberleninka.ru/article/n/2000-02-037-smakotina-n-l-osnovy-sotsiologiinestabilnosti-i-riska-filosofskiy-sotsiologicheskiy-i-sotsialno-psihologicheskiyaspekty-m

23. K.A. Feofanov, Civilization theory of modernization (Dashkov and $\mathrm{K}^{\circ}$, Moscow, 2019)

24. O.N. Yanitsky, Sociology. Ethnology 12(1) (2003)

25. S.I. Chernykh, I.G. Borisenko, International interdisciplinary collective monograph. Comp. (Encyclopedist-Maximum, Moscow, 2020)

26. J. Delors, Learning: The treasure within (Unesco, Paris, 1998) http://www.ifap.ru/library/book201.pdf

27. M.S. Guseltseva, M.M. Konchalovskaya, G.R. Khuzeeva, World of Psychology 1, 236249 (2016) 